\title{
Photobleaching as a factor controlling spectral characteristics of chromophoric dissolved organic matter in open ocean
}

\author{
Y. Yamashita ${ }^{1,2}$, Y. Nosaka ${ }^{2}$, K. Suzuki ${ }^{1,2}$, H. Ogawa ${ }^{3}$, K. Takahashi ${ }^{4}$, and H. Saito \\ ${ }^{1}$ Faculty of Environmental and Earth Science, Hokkaido University, N10, W5, Kita-ku, Sapporo, Hokkaido 060-0810, Japan \\ ${ }^{2}$ Graduate School of Environmental Science, Hokkaido University, N10, W5, Kita-ku, Sapporo, Hokkaido 060-0810, Japan \\ ${ }^{3}$ Atmosphere and Ocean Research Institute, The University of Tokyo, 5-1-5, Kashiwanoha, \\ Kashiwa-shi, Chiba 277-8564, Japan \\ ${ }^{4}$ Graduate School of Agricultural and Life Sciences, The University of Tokyo, 1-1-1, Yayoi, \\ Bunkyo-ku, Tokyo, 113-8657, Japan \\ ${ }^{5}$ Tohoku National Fisheries Research Institute, Fisheries Research Agency, 3-27-5 Shinhama-cho, Shiogama 985-0001, Japan
}

Correspondence to: Y. Yamashita (yamashiy@ees.hokudai.ac.jp)

Received: 10 May 2013 - Published in Biogeosciences Discuss.: 19 June 2013

Revised: 11 September 2013 - Accepted: 11 October 2013 - Published: 12 November 2013

\begin{abstract}
Chromophoric dissolved organic matter (CDOM) ubiquitously occurs in marine environments and plays a significant role in the marine biogeochemical cycles. Basin scale distributions of CDOM have recently been surveyed in the global ocean and indicate that quantity and quality of oceanic CDOM are mainly controlled by in situ production and photobleaching. However, factors controlling the spectral parameters of CDOM in the UV region, i.e., spectral slope of CDOM determined at $275-295 \mathrm{~nm}\left(S_{275-295}\right)$ and the ratio of two spectral slope parameters $\left(S_{\mathrm{R}}\right)$; the ratio of $S_{275-295}$ to $S_{350-400}$, have not been well documented. To evaluate the factor controlling the spectral characteristics of CDOM in the UV region in the open ocean, we determined the quantitative and qualitative characteristics of CDOM in the subarctic and subtropical surface waters $(5-300 \mathrm{~m})$ of the western North Pacific. Absorption coefficients at $320 \mathrm{~nm}$ in the subarctic region were higher than those in the subtropical region throughout surface waters, suggesting that magnitudes of photobleaching were different between the two regions. The values of $S_{275-295}$ and $S_{\mathrm{R}}$ were also higher in the subtropical region than the subarctic region. The dark microbial incubation showed biodegradation of DOM little affected $S_{275-295}$, but slightly decreased $S_{\mathrm{R}}$. On the other hand, increases in $S_{275-295}$ and relative stableness of $S_{R}$ were observed during photo-irradiation incubations respectively. These experimental results indicated that photobleaching of $\mathrm{CDOM}$ mainly induced qualitative differences in CDOM at
\end{abstract}

UV region between the subarctic and subtropical surface waters. The results of this study imply that $S_{275-295}$ can be used as a tracer of photochemical history of CDOM in the open ocean.

\section{Introduction}

Chromophoric dissolved organic matter (CDOM) ubiquitously occurs in the open ocean (Kitidis et al., 2006; Nelson et al., 2007, 2010; Swan et al., 2009; Yamashita and Tanoue, 2009). CDOM is one of the major factors controlling optical properties of seawater (Siegel et al., 2002; Nelson and Siegel, 2013), and thus, controls the light penetration, especially, in the UV region (Fichot et al., 2008; Nelson and Siegel, 2013), which affects the primary production and microbial production, and also the structure of the marine food web (Smith et al., 1992; Herndl et al., 1993; Häder et al., 1998). CDOM is also known to be an important player in biogeochemical cycles since it is photo-reactive and is destroyed upon exposure to sunlight, producing inorganic carbon, volatile species such as carbonyl sulfide, and bioavailable low molecular weight DOM (Mopper and Kieber, 2002).

The distributions of CDOM in coastal environments are strongly controlled by riverine inputs of terrestrial (allochthonous) CDOM (Blough and Del Vecchio, 2002). However, the major fraction of CDOM in the open ocean has been 
considered to be produced autochthonously through various biological processes (Nelson et al., 2004; Steinberg et al. 2004; Ortega-Retuerta et al., 2009; Shank et al., 2010), and the primary local source of CDOM has been assigned to microbial activity (Nelson et al., 2004; Yamashita and Tanoue, 2004). From the global distribution of CDOM, microbially produced CDOM has been considered biologically refractory components with the time scale of the thermohaline circulation (Nelson et al., 2007, 2010; Yamashita and Tanoue, 2008; Swan et al., 2009), and thus, CDOM has been suggested as a tracer of deep ocean biogeochemical processes and circulation (Nelson et al., 2007, 2010). As such, the distribution of CDOM in the open ocean is basically controlled by a balance between autochthonous production and photobleaching under the influence of transport by vertical mixing, ventilation, and upwelling of water masses.

The composition of CDOM can be determined by the spectral slope parameter $(S)$, and $S$ of CDOM in the open ocean has known to be different among sources (Kitidis et al., 2006; Yamashita and Tanoue, 2009). $S$ has also known to change with photobleaching (Swan et al., 2012) or diagenesis (Nelson et al., 2007) of CDOM. Thus, $S$ can be legitimately employed to address CDOM "history" including the sources and biogeochemical processing. However, lack of standard method to determine the $S$ limits its usefulness since its value depends on the wavelength range for estimation (Carder et al., 1989; Stedmon et al., 2000; Twardowski et al., 2004). Recently, the ratio of the spectral slope parameters $\left(S_{\mathrm{R}}\right)$ obtained from two wavelength ranges, i.e., $S$ at 275 to $295 \mathrm{~nm}$ $\left(S_{275-295}\right)$ to 350 to $400 \mathrm{~nm}\left(S_{350-400}\right)$, was introduced as an index of molecular weight of DOM and/or photobleaching history (Helms et al., 2008). The $S_{\mathrm{R}}$ has been widely applied to evaluating the environmental dynamics of DOM in terrestrial aquatic environments (e.g. Yamashita et al., 2010a, b; Osburn et al., 2011; Mladenov et al., 2011) as well as coastal environments (Guéguen et al., 2011; Shank and Evans, 2011; Romera-Castillo et al., 2013). In addition, $S_{275-295}$ was successfully used as a retrieval method of DOC concentration and as a tracer of terrestrial DOC in river-influenced ocean margin (Fichot and Benner, 2011, 2012; Fichot et al., 2013). Since $S_{275-295}$ can be measured with high precision due to relatively high absorbance levels in this wavelength range (Helms et al., 2008), these spectral parameters may also be used as a tracer of water masses and biogeochemical history of CDOM in the open ocean where CDOM levels are quite low (Nelson et al., 2007, 2010; Swan et al., 2009; Yamashita and Tanoue, 2009). Although changes in $S_{\mathrm{R}}$ and $S_{275-295}$ along with photobleaching of deep ocean DOM have recently been reported (Stubbins et al., 2012; Helms et al., 2013), the distribution of these parameters has not been evaluated in the open ocean thus far.

Since the levels of CDOM in the open ocean are basically controlled by microbial production, photobleaching, and transport as mentioned above, the levels of CDOM in the surface water is higher in subpolar regions compared

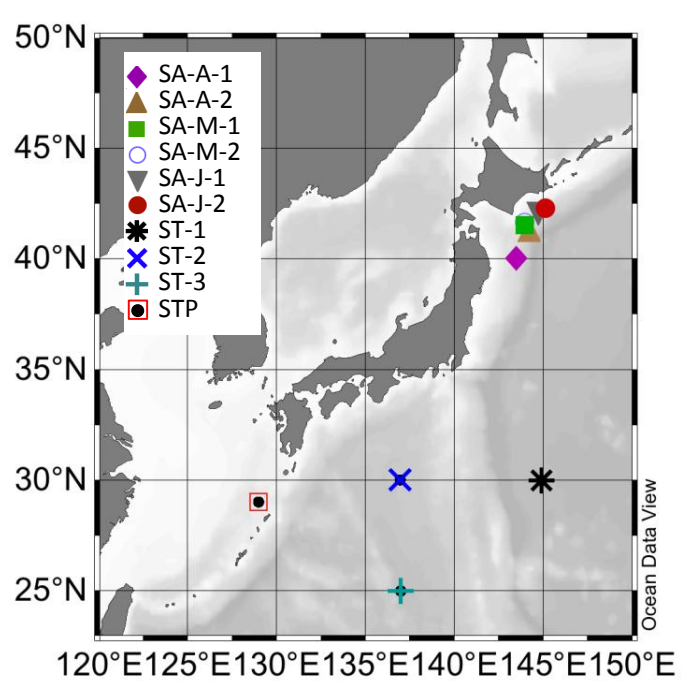

Fig. 1. Sampling locations. Samples for photo-irradiation experiments were collected from the station located at $29.0^{\circ} \mathrm{N}, 129.0^{\circ} \mathrm{E}$ (STP).

with subtropical regions due to extensive photobleaching of CDOM at subtropical regions (Nelson et al., 2007, 2010; Swan et al., 2009; Yamashita and Tanoue, 2009). Thus, it can be hypothesized that $S_{\mathrm{R}}$ and $S_{275-295}$ in the subpolar surface water are different from those in the subtropical surface water due to different photobleaching history of CDOM, and thus, these parameters can be used as biogeochemical tracers in the open ocean. In this study, we determined the spectral characteristics of CDOM, including $S_{\mathrm{R}}$ and $S_{275-295}$, in the upper $300 \mathrm{~m}$ of the subarctic and the subtropical regions at the western North Pacific. In addition, in order to examine $S_{\mathrm{R}}$ and $S_{275-295}$ as potential biogeochemical tracers, the changes in CDOM spectral characteristics along with photobleaching of CDOM and microbial degradation of DOM were evaluated.

\section{Materials and methods}

\subsection{Observation and sample collection}

Sampling locations are shown in Fig. 1. Samplings of the subarctic region were carried out at 2 stations (SA-A-1, SA-A-2) on 20 April 2010 by the R/V Wakataka-maru (WK1004), at 2 stations (SA-J-1, SA-J-2) from 9 to 11 June 2010 by the R/V Wakataka-maru (WK1006), and at 2 stations (SA-M-1, SA-M-2) from 10 to 11 May 2011 by the R/V Tansei Maru (KT-11-07). Samplings of the subtropical region were carried out at 3 stations (ST-1, ST-2, ST-3) from 19-20 May 2010 during the R/V Hakuhou Maru cruise (KH10-01).

Seawater samples for CDOM analyses were collected from $5 \mathrm{~m}$ to $300 \mathrm{~m}$ at the above mentioned 9 stations with a 
Table 1. Sample details for dark microbial incubations and photo-irradiation experiments.

\begin{tabular}{|c|c|c|c|c|c|c|c|c|c|c|}
\hline Experiment & Type & Location & $\begin{array}{l}\text { Depth } \\
\text { (m) }\end{array}$ & $\begin{array}{l}\text { Temp. } \\
\left({ }^{\circ} \mathrm{C}\right)\end{array}$ & Salinity & $\begin{array}{l}\text { Chl } a \\
\left(\mu \mathrm{gL}^{-1}\right)\end{array}$ & $\begin{array}{l}a_{320} \\
\left(\mathrm{~m}^{-1}\right)\end{array}$ & $\begin{array}{l}S_{275-295} \\
\left(\mathrm{~nm}^{-1}\right)\end{array}$ & $\begin{array}{l}S_{350-400} \\
\left(\mathrm{~nm}^{-1}\right)\end{array}$ & $S_{\mathrm{R}}$ \\
\hline SAM-1 & Microbial incubation & $41.7^{\circ} \mathrm{N}, 144.0^{\circ} \mathrm{E}$ & 5 & 4.5 & 32.88 & 1.22 & 0.284 & 0.0303 & 0.0141 & 2.15 \\
\hline SAM-2 & Microbial incubation & $41.5^{\circ} \mathrm{N}, 144.0^{\circ} \mathrm{E}$ & 5 & 4.4 & 32.99 & 2.06 & 0.398 & 0.0279 & 0.0136 & 2.05 \\
\hline STP-1 & Photo-irradiation & $29.0^{\circ} \mathrm{N}, 129.0^{\circ} \mathrm{E}$ & 400 & 14.3 & 34.52 & & 0.158 & 0.0294 & 0.0134 & 2.20 \\
\hline STP-2 & Photo-irradiation & $29.0^{\circ} \mathrm{N}, 129.0^{\circ} \mathrm{E}$ & 766 & 5.7 & 34.35 & & 0.216 & 0.0216 & 0.0127 & 1.70 \\
\hline
\end{tabular}

CTD carousel system equipped with Niskin bottles. The plastic in-line filter holder that contained pre-combusted $\left(450^{\circ} \mathrm{C}\right.$, $3-5 \mathrm{~h})$ glass fiber filter $(0.7 \mu \mathrm{m}$ of nominal pore size, Whatman GF/F,) was attached directly to the spigot of Niskin bottles, and seawater was gravity filtered into pre-combusted glass vial with teflon-lined cap after triple rinsing. The samples were then stored frozen in the dark until analysis. All the equipment, except glassware were pre-soaked in 5-10\% $\mathrm{HCl}$ and rinsed thoroughly with Milli-Q water.

Chlorophyll $a(\mathrm{Chl} a)$ concentrations were determined using two methods. For samples form the subarctic region, high-performance liquid chromatography (HPLC) was used following Endo et al. (2013). Chl $a$ concentrations at the subtropical region were determined by the fluorometric method of Welschmeyer (1994).

\subsection{Microbial incubation experiments}

To evaluate the changes in CDOM quantity and quality during microbial degradation of bioavailable DOM, seawater bottle incubation experiments were performed according to Hasegawa et al. (2010). Seawater samples were collected from $5 \mathrm{~m}$ at two stations in the subarctic region on 10 May 2011 during the KT-11-07 cruise (Table 1). Seawater was gravity filtered using GF F filter into pre-cleaned $20 \mathrm{~L}$ polycarbonate bottles after triple rinsing, and the filtrate was then dispensed into 24 pre-combusted glass bottles with teflonlined caps after triple rinsing. Half of the glass bottles containing the $\mathrm{GF} / \mathrm{F}$ filtrate were incubated in the dark room temperature $\left(16-25^{\circ} \mathrm{C}\right)$ and others were incubated in the dark in a refrigerator $\left(1-6^{\circ} \mathrm{C}\right)$ that was close to surface seawater temperature (Table 1). Triplicate samples for each treatment were sequentially collected at 10,20, and 40 days from a set of experimental bottles and filtered using pre-combusted GF/F filter, and then stored frozen in the dark until analysis.

\subsection{Photo-irradiation experiments}

Seawater samples were collected from $400 \mathrm{~m}$ and $766 \mathrm{~m}$ at the subtropical region (Fig. 1, Table 1) on 19 November 2012 during the cruise of R/V Tansei Maru (KT-12-31). The large surface area $0.2 \mu \mathrm{m}$ capsule filter ( $\mathrm{HCl}$ pre-cleaned AcroPak, Pall) was attached directly to the spigot of Niskin bottles, and seawater was gravity filtered into pre-cleaned $9 \mathrm{~L}$ polycarbonate bottles after triple rinsing. The filtrate was kept in the dark at $\sim 4^{\circ} \mathrm{C}$ until photo-irradiation experiments con- ducted on land. Eighteen $50 \mathrm{~mL}$ quartz bottles were filled with the filtered seawater sample after triple rinsing. Then, 9 out of the 18 bottles were wrapped with aluminum foil. The quartz bottles containing the filtrate were incubated in the water bath on the roof of the Environmental Science building, Hokkaido University $\left(43.1^{\circ} \mathrm{N}, 141.3^{\circ} \mathrm{E}\right)$ under natural sunlight for 13 days. The water bath maintained a temperature between 3 and $10^{\circ} \mathrm{C}$ throughout the irradiation during daytime, and the quartz bottles were kept in the refrigerator $\left(\sim 4{ }^{\circ} \mathrm{C}\right)$ during nighttime. On the days of 2,6 , and 13 of the incubation, three replicate samples for each treatment were allowed to stand in the dark until reaching near room temperature (approx. $23^{\circ} \mathrm{C}$ ), and then, absorbance analyses were carried out without further filtration. The global solar radiation was measured by a pyranometer (SR507, Field Pro) installed on the roof of the Environmental Science building. The cumulative irradiance was 23,60 , and $87 \mathrm{MJ} \mathrm{m}^{-2}$ for 2 , 6 , and 13 days, respectively.

\subsection{Absorbance measurements}

Water samples were thawed and allowed to stand until reaching room temperature (approx. $23^{\circ} \mathrm{C}$ ) prior to absorbance measurements. Absorbance spectra were obtained between 200 and $1000 \mathrm{~nm}$ at $0.5 \mathrm{~nm}$ intervals using a spectrophotometer (UV-1800, Shimadzu). A $10 \mathrm{~cm}$ quartz-windowed cell was used for the absorbance analysis. Due to limited sample volumes, a $5 \mathrm{~cm}$ quartz-windowed cell was used for the samples obtained from photo-irradiation experiments. Absorbance spectra of a blank (Milli-Q) and samples were obtained against air, and a blank spectrum was subtracted from each sample spectrum. Sample spectra were baselinecorrected by subtracting average values ranging from 590 to $600 \mathrm{~nm}$ from the entire spectrum (Yamashita and Tanoue, 2009), and then converted to absorption coefficients, $a(\lambda)$ $\left(\mathrm{m}^{-1}\right)$ (Green and Blough, 1994). CDOM absorption spectra are declining exponentially with wavelength (Fig. 2) and have usually been fit to an exponential function as follows (Green and Blough, 1994):

$a(\lambda)=a(\lambda i) e^{-S(\lambda-\lambda i)}$,

where $a(\lambda)$ and $a(\lambda i)$ are the absorption coefficients at wavelength $\lambda$ and reference wavelength $\lambda i\left(\mathrm{~m}^{-1}\right)$, respectively. $S$ is the spectral slope parameter $\left(\mathrm{nm}^{-1}\right)$. The absorption coefficient at $320 \mathrm{~nm}, a(320)$, was reported as a quantitative 


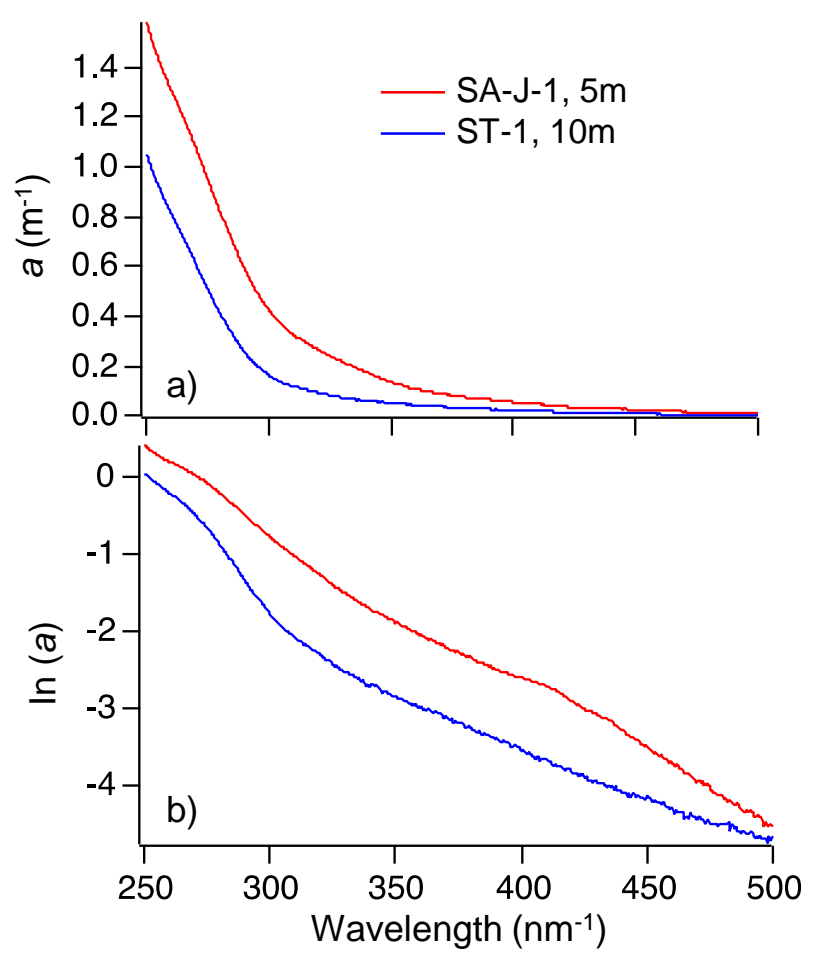

Fig. 2. Typical absorption spectrum at the subarctic (SA-J-1, $5 \mathrm{~m}$ ) and the subtropical (ST-1, 10 m) regions: (a) on a linear scale and (b) on a logarithmic scale.

parameter of CDOM (Yamashita and Tanoue, 2009). The $S_{\mathrm{R}}$ value, the ratio of the $S$ obtained from the two regions, 275 to $295 \mathrm{~nm}\left(S_{275-295}\right)$ and 350 to $400 \mathrm{~nm}\left(S_{350-400}\right)$, was calculated according to Helms et al. (2008).

Specifications for the spectrophotometer (UV-1800) provided by the manufacture are as follows; photometric repeatability is less than \pm 0.001 optical density (OD) unit at an absorbance of $0.5 \mathrm{OD}$ and noise level is less than 0.00005 . The $0.001 \mathrm{OD}$ corresponds to absorption coefficients of 0.023 and $0.046\left(\mathrm{~m}^{-1}\right)$ for $10 \mathrm{~cm}$ and $5 \mathrm{~cm}$ measurements, respectively. These values occur around $350-400 \mathrm{~nm}$ and $400-450 \mathrm{~nm}$ for the subtropical and subarctic surface waters, respectively (Fig. 2). We also determined errors associated with the spectrophotometer by triplicate measurements of two subtropical surface waters with $5 \mathrm{~cm}$ cells. The results (average \pm standard deviation) were as follows; Sample 1: $a(320)=0.108 \pm 0.003 \mathrm{~m}^{-1}, S_{275-295}=0.0408$ $\pm 0.0004 \mathrm{~nm}^{-1}, S_{350-400}=0.0131 \pm 0.0004 \mathrm{~nm}^{-1}, S_{\mathrm{R}}=$ $3.11 \pm 0.08$, and Sample 2: $a(320)=0.082 \pm 0.003 \mathrm{~m}^{-1}$, $S_{275-295}=0.0459 \pm 0.0004 \mathrm{~nm}^{-1}, S_{350-400}=0.0164 \pm$ $0.0018 \mathrm{~nm}^{-1}, S_{\mathrm{R}}=2.82 \pm 0.35$. Thus, even though we only used the $5 \mathrm{~cm}$ cell for photo-irradiation experiments of deep water samples that contained relatively high levels of CDOM (Table 1), the results of $S_{350-400}$ and $S_{\mathrm{R}}$ might have relatively large analytical errors.

\section{Results}

\subsection{Vertical profiles of salinity, temperature, and $\mathrm{Chl} a$}

Salinity ranges in the upper $300 \mathrm{~m}$ water column of the subarctic region were 32.9-33.7, 32.9-33.8, and 32.9-33.7 in April, May, and June, respectively (Fig. 3). Temperature ranged from 2.4 to $4.5^{\circ} \mathrm{C}$ in April, 2.0 to $4.7^{\circ} \mathrm{C}$ in May, and 0.6 to $9.0^{\circ} \mathrm{C}$ in June. These water masses could be categorized as a cold subarctic Oyashio water according to the criterion of a temperature of $<5^{\circ} \mathrm{C}$ at a depth of $100 \mathrm{~m}$ (Kawai, 1972). The Oyashio is a mixture of the western boundary current of the western subarctic gyre in the North Pacific and the Sea of Okhotsk (Yasuda, 2004). Chl $a$ concentrations were different among the sampling periods, i.e., $\sim 8.8 \mu \mathrm{g} \mathrm{L}^{-1}$ in April, $\sim 2.3 \mu \mathrm{g} \mathrm{L}^{-1}$ in May, and $\sim 0.7 \mu \mathrm{g} \mathrm{L}^{-1}$ in June. From the Chl $a$ concentration, April, May, and June could be categorized as spring bloom, decline of the bloom, and post bloom phase, respectively (Saito et al., 2002).

Salinity and temperature at 3 stations of the subtropical region ranged from 34.7 to 35.0 and 16.6 to $26.4{ }^{\circ} \mathrm{C}$, respectively. The highest temperature and salinity were evident in the upper $150 \mathrm{~m}$ waters at ST-3 near the central part of the subtropical gyre. Chl $a$ concentrations at the subtropical region were quite low (less than $0.6 \mu \mathrm{g} \mathrm{L}^{-1}$ ) compared to the subarctic region and showed subsurface maxima at 74,70 and $114 \mathrm{~m}$ at ST-1, ST-2, and ST-3, respectively.

\subsection{Vertical profiles of CDOM quantity and quality}

Levels of CDOM were higher in the subarctic region compared with the subtropical region (Fig. 2). $a(320)$, ranged from 0.253 to $0.372 \mathrm{~m}^{-1}$ in the subarctic region and from 0.056 to $0.159 \mathrm{~m}^{-1}$ in the subtropical region (Fig. 3). The values of $a(320)$ in each region were similar with those in the subarctic and subtropical surface waters of the central North Pacific, respectively (Yamashita and Tanoue, 2009) and were similar with or slightly higher than $a(325)$ in the surface waters of the Pacific (Swan et al., 2009). In the subarctic region, the levels of $a(320)$ and Chl $a$ in the upper water column $(\sim 50 \mathrm{~m})$ were higher than those in the lower water column irrespective of differences in sampling periods. However, the temporal change in $a(320)$ in the upper water column did not coincide with that in $\mathrm{Chl} a$ concentrations in the Oyashio waters. The lowest value of $a(320)$ in this study was found at ST-3 in the subtropical region. At ST-3, $a(320)$ tended to increase with depth. The levels of $a(320)$ at ST-1 and ST2 showed subsurface maxima at $50 \mathrm{~m}$ which were shallower than the subsurface $\mathrm{Chl} a$ maxima.

Figure $2 \mathrm{~b}$ shows a typical absorption spectrum on logarithmic scale at the subarctic and subtropical regions. At the wavelengths shorter than $300 \mathrm{~nm}$, the decline of absorption spectrum with wavelength was steeper for the subtropical region than the subarctic region. Values of $S_{275-295}$ were high at the subtropical region $\left(0.0339-0.0556 \mathrm{~nm}^{-1}\right)$, especially 

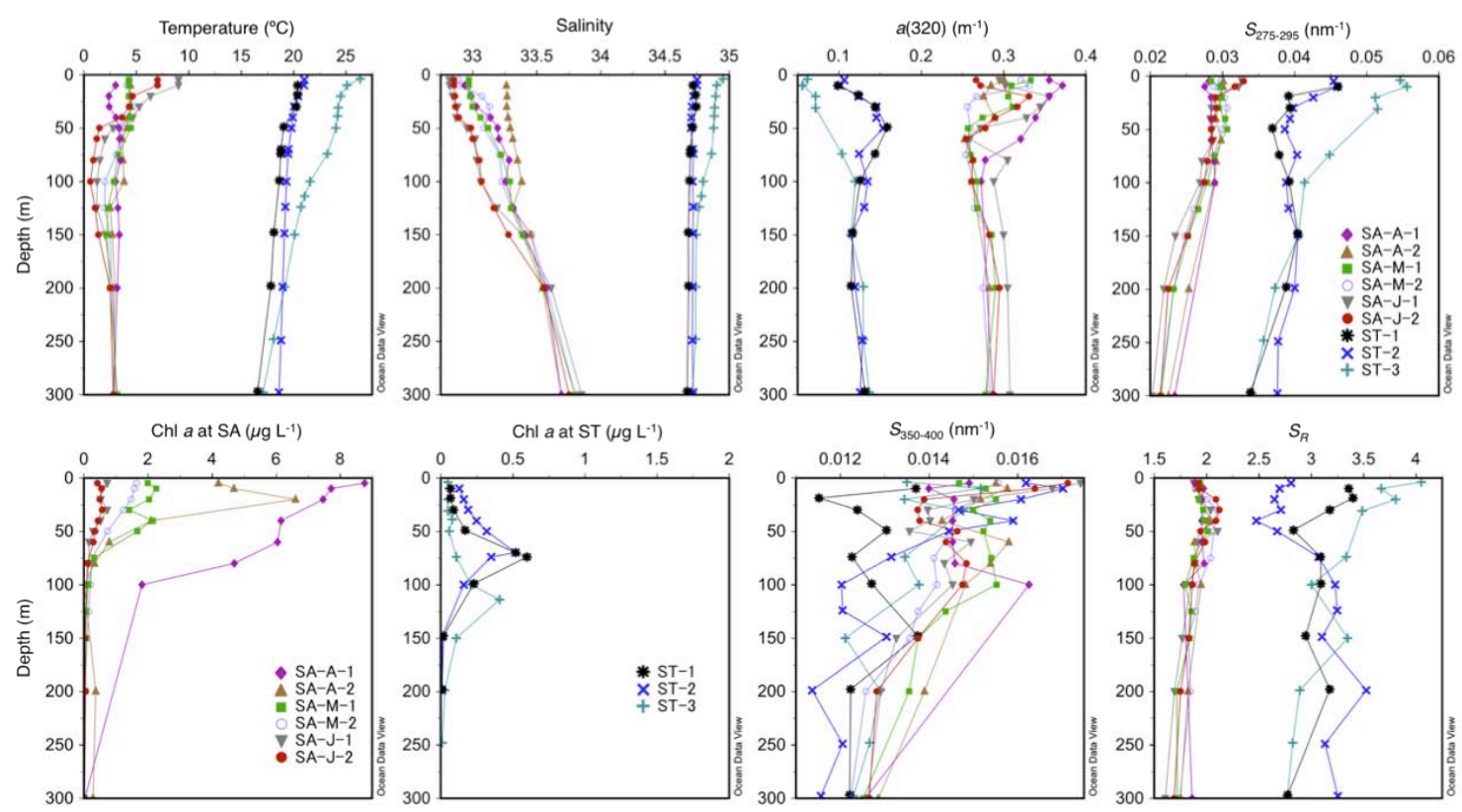

Fig. 3. Vertical profiles of temperature, salinity, chlorophyll $a$ concentration, $a(320), S_{275-295}, S_{350-400}$, and $S_{\mathrm{R}}$ at the subarctic region (SA) and the subtropical region (ST). Note: ranges of $x$-axis for chlorophyll $a$ concentration were different between SA and ST.

in the upper $100 \mathrm{~m}$ at ST-3, compared with the subarctic region $\left(0.0203-0.0330 \mathrm{~nm}^{-1}\right)$ but decreased with depth, irrespective of differences in oceanic regions (Fig. 3). The values of $S_{275-295}$ at the subarctic region were similar irrespective of differences in sampling periods, even though $S_{275-295}$ of surface water $(5-10 \mathrm{~m})$ in June were slightly higher than those in April and May. The range of $S_{275-295}$ observed in this study was higher than those in river waters (Helms et al., 2008; Spencer et al., 2012), but $S_{275-295}$ in the subarctic waters were similar to those found in the Hudson Bay and Hudson Strait (Guéguen et al., 2011; Granskog, 2012). $S_{275-295}$ in the subtropical waters were similar to those in the high salinity Gulf of Mexico waters (Fichot and Benner, $2012)$ as well as surface water $(5 \mathrm{~m})$ of the central North Pacific (Helms et al., 2013).

$S_{350-400}$ tended to decrease as depth increased irrespective of difference in oceanic regions, and the values were not different between the subarctic and subtropical regions. The ranges of $S_{350-400}$ ( 0.0114 to $0.0174 \mathrm{~nm}^{-1}$ for all samples) found in this study were relatively smaller than those found in river waters (Helms et al., 2008; Spencer et al., 2012), but were similar with those found in the high salinity Gulf of Mexico waters (Fichot and Benner, 2012).

Significant difference in $S_{\mathrm{R}}$, basically due to difference in $S_{275-295}$, was also evident between the subarctic and the subtropical waters. Interestingly, vertical profiles of $S_{\mathrm{R}}$ in the subarctic region showed small subsurface maxima at depths between 30 and $80 \mathrm{~m}$. Vertical profiles of $S_{\mathrm{R}}$ did not show any clear increase or decrease trends among the 3 stations in the subtropical region. The range of $S_{\mathrm{R}}$ found in the sub- arctic waters (1.61-2.12) was similar to those found in deep ocean DOM (Stubbins et al., 2012; Helms et al., 2013) but was generally higher than that in the river waters (Helms et al., 2008; Yamashita et al., 2010a, b; Spencer et al., 2012) and in the Hudson Bay (Granskog, 2012). The $S_{\mathrm{R}}$ in the subtropical waters ranged from 2.48 to 4.05 . These values were similar to that found for the Georgia Bight but smaller than that found for the surface waters of the Sargasso Sea and the central North Pacific (Helms et al., 2008, 2013).

\subsection{Changes in CDOM during dark microbial incubations}

Figure 4 shows the changes in CDOM quantity and quality during dark microbial incubation. Hasegawa et al. (2010) conducted similar experiments for 15 to 38 days using GF/F filtrate of Oyashio waters collected during pre-bloom, bloom, and post-bloom phases and found that $2.1-8.3 \%$ of initial DOC was consumed by bacteria. Thus, the microbial degradation of DOM could occur during the dark microbial incubations in this study. Even though different temperatures, i.e., room and cool temperatures, were used for dark microbial incubations, differences in quantitative and qualitative parameters of CDOM during incubations were not clear between them. The levels of CDOM, $a(320)$, decreased with time during incubations at the cool temperature. The decrease in $a(320)$ during the SAM-2 cool incubation was larger than that of the SAM-1 cool incubation. At room temperature, $a(320)$ sharply decreased for the first 10 days, then did not change over the SAM-2 room incubation, whereas, 
$a(320)$ sharply increased for first 10 days, and then decreased from 10 to 40 days for the SAM-1 room incubation. Such changes in CDOM quantity during dark incubations could be explained by the combination of degradation of bioavailable fraction and microbial production (Nelson et al., 2004; Biers et al., 2007). The magnitudes of change in $a(320)$ $\left(\sim 0.067 \mathrm{~m}^{-1}\right)$ during 40 day incubations were comparable to its spatial and temporal differences observed in the surface waters of the subarctic region (Fig. 3).

$S_{275-295}$ did not change systematically during incubations. Compared with the initial values $(d=0)$, the changes in $S_{275-295}$ were less than $0.0011 \mathrm{~nm}^{-1}$ during 40 days incubations with one exception $\left(0.0027 \mathrm{~nm}^{-1}\right.$ for SAM-1 room at 10 days). The magnitudes of change in $S_{275-295}$ during dark incubations were quite small compared with the ranges observed for vertical differences $\left(\sim 0.01 \mathrm{~nm}^{-1}\right.$ at the subarctic region, $\sim 0.02 \mathrm{~nm}^{-1}$ at the subtropical region, Fig. 3). On the other hand, $S_{350-400}$ increased throughout the incubations at increments of $0.0012-0.0018 \mathrm{~nm}^{-1}$ for 40 day. The net increments in $S_{350-400}$ during incubation were comparable to those found for vertical differences in the subtropical and the subarctic regions (Fig. 3). As a result of changes in $S_{275-295}$ and $S_{350-400}, S_{\mathrm{R}}$ continued to decrease during incubations. The net decrements of $S_{\mathrm{R}}$ during 40 day incubations (0.15$0.26)$ were similar with vertical differences found in the subarctic region (Fig. 3).

\subsection{Changes in CDOM during photo-irradiation experiments}

Levels of $a(320)$ were decreased for light treatments but not for dark experiments during photo-irradiation experiments (Fig. 5), indicating the photobleaching of CDOM during natural sunlight irradiation. The net decreases in $a(320)$ were 0.068 and $0.081 \mathrm{~m}^{-1}$ for STP-1 and STP-2 light experiments, respectively. Such magnitudes of decrease in $a(320)$ for 13 day photo-irradiation were comparable to its spatial and temporal differences found in the surface waters of the subarctic region (Fig. 3). During the photobleaching of CDOM, $S_{275-295}$ continued to increase with the increment of 0.0093 and $0.0067 \mathrm{~nm}^{-1}$ for 13 day STP-1 and STP-2 light experiments, respectively. It should be noted that this range was one order of magnitude greater than that found during 40 day dark microbial incubations. On the other hand, the values of $S_{275-295}$ were constant throughout the experiments for STP-1 and STP-2 dark experiments. $S_{350-400}$ also tended to increase with increment of $0.0027-0.0039 \mathrm{~nm}^{-1}$ for 13 day during photobleaching of $\mathrm{CDOM}$, even though the values were largely scattered among the three replicates. $S_{350-400}$ at dark treatments also tended to increase for 13 days experiments, implying that increases in $S_{350-400}$ observed during photobleaching of CDOM might be overestimated. As a result, $S_{\mathrm{R}}$ did not exhibit large variations for the three replicates throughout the photo-irradiation experiments.
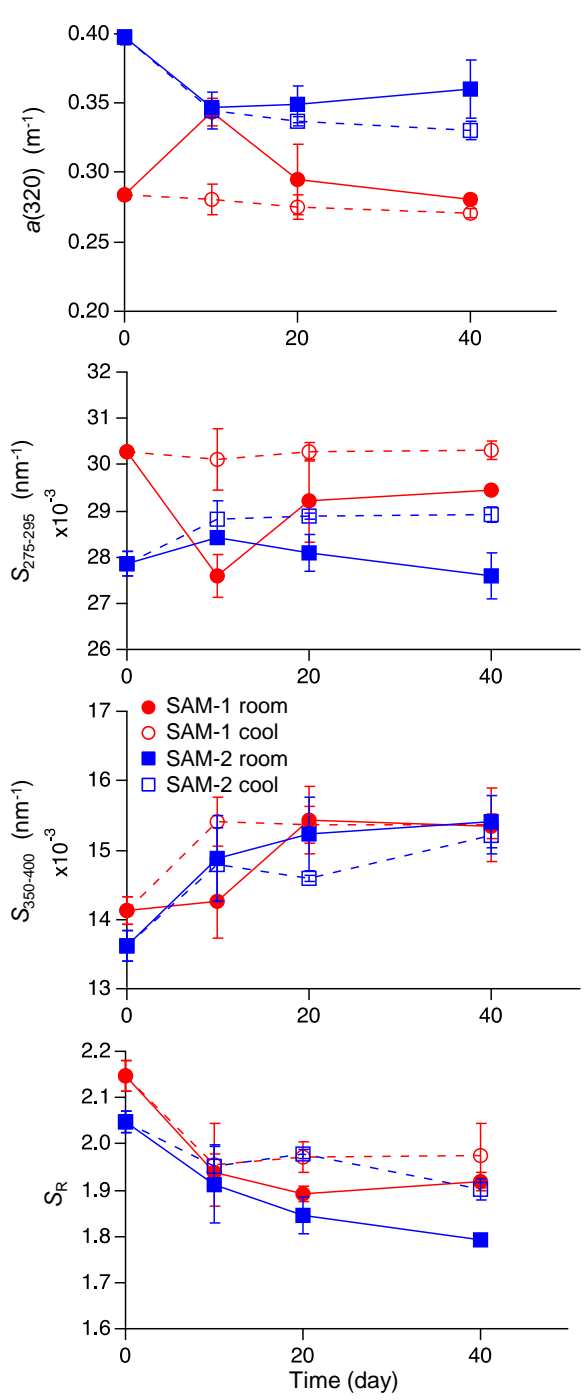

Fig. 4. Changes in $a(320), S_{275-295}, S_{350-400}$, and $S_{\mathrm{R}}$ during dark microbial incubation experiments of the subarctic surface waters for 40 days.

\section{Discussion}

\subsection{Factors controlling the CDOM level at the subarctic and the subtropical region}

The water masses of the subarctic region were categorized as Oyashio water, irrespective of differences in sampling month, from temperature distributions. The Oyashio is the western boundary current of the western subarctic gyre in the North Pacific, however, Oyashio water is influenced by marginal sea waters, i.e., Okhotsk Sea water (Yasuda, 2004). Thus, terrestrial CDOM might contribute to the subarctic waters, especially in the upper $50 \mathrm{~m}$ where $a(320)$ were relatively high compared with deeper waters (Fig. 3). Values of $a(320)$ only weakly correlated with salinity in the upper 
$50 \mathrm{~m}(R=-0.39, p=0.04, n=29)$, implying that the contribution of terrestrial CDOM was much smaller as compared with autochthonous CDOM.

The accumulation of DOC along with phytoplankton bloom events has been observed for the Oyashio waters of the subarctic region (Hasegawa et al., 2010). On the other hand, the levels of CDOM, namely $a(320)$, in the subarctic region did not change along with phytoplankton bloom events, i.e., bloom (April), the decline of bloom (May), and post bloom (June) phases, indicating that major factors controlling the bulk DOM and CDOM levels are different and phytoplankton is not major source of CDOM in this study area (Fig. 3). At the BATS site in the Sargasso Sea, the seasonal cycle of CDOM level has been considered the result of photobleaching, winter convective mixing, and production during heterotrophic recycling of organic carbon rather than primary production (Nelson et al., 1998; Nelson and Siegel, 2002). The microbial production of CDOM has also been observed during microbial culture experiments (Nelson et al., 2004; Biers et al., 2007; Ortega-Retuerta et al., 2009). On the other hand, various biological sources, i.e., zooplankton (Steinberg et al., 2004; Ortega-Retuerta et al., 2009), cyanobacteria Trichodesmium spp. (Steinberg et al., 2004), and dinoflagellates (Vernet and Whitehead, 1996) have been considered as sources of CDOM. The CDOM derived from such specific sources usually have a distinct peak in absorbance spectra. In the present study, distinct peaks were not evident in CDOM spectra (Fig. 2). In addition, spectral slope parameters, i.e., $S_{275-295}, S_{350-400}$, and $S_{\mathrm{R}}$, were not different among sampling periods in the subarctic region, suggesting that heterotrophic microbial regeneration, rather than phytoplankton and zooplankton activity, seems to be a major source of CDOM for the Oyashio waters at the subarctic region.

The higher levels of CDOM in the upper-50 $\mathrm{m}$ waters compared with $50-30 \mathrm{~m}$ waters were possibly due to higher microbial production. Kobari et al. (2010) reported that bacterial abundance and growth were not related to $\mathrm{Chl} a$ concentration during the spring phytoplankton bloom events in the Oyashio region. The active regeneration with high bacterial production was observed after the peak of primary production during in situ iron enrichment experiments conducted at the subarctic region of the western North Pacific (Kudo et al., 2009). However, in the present study, the highest levels of CDOM did not occur during the decline of bloom (May) or post bloom (June) phases. Such a temporal pattern of CDOM level suggests that degradation of newly produced CDOM is an important factor controlling the CDOM level in the Oyashio waters at the subarctic region. The photobleaching that causes a decrease in CDOM level occurs with a time scale of hours to days (Fig. 5; Swan et al., 2012). The microbial culture incubation experiments have highlighted the production of a bioavailable CDOM fraction that is quickly degraded by microbes within days (Nelson et al., 2004; Biers et al., 2007). Our dark microbial incubation experiments also showed net decrease in CDOM with one exception (Fig. 4). These pieces of evidence suggested that major fractions of newly produced CDOM might disappear rapidly due to the photobleaching and/or microbial degradation. Interestingly, subsurface maxima of CDOM levels were clearly observed for $20-30 \mathrm{~m}$ at SA-J-1 and SA-J-2 (Fig. 3), suggesting either photobleaching dominated in surface waters $(<20 \mathrm{~m})$ or freshly produced CDOM accumulated in the subsurface layer $(20-30 \mathrm{~m})$ during the post bloom phase.

The levels of CDOM in the subtropical region were lower than those in the subarctic region throughout the water column (Fig. 3). Such differences in CDOM level (subarctic > subtropical) have also been found for basin scale observations of CDOM (Kitidis et al., 2006; Nelson et al., 2007; 2010; Swan et al., 2009; Yamashita and Tanoue, 2009) as well as satellite observations of CDOM (e.g. Siegel et al., 2002; Bricaud et al., 2012). Low levels of CDOM in the lower water column due to contribution of mode water have also been observed in subtropical regions (Nelson et al., 2007, 2010; Yamashita and Tanoue, 2009; Swan et al., 2009). The low levels of CDOM found in the subtropical region has been explained by extensive photobleaching of CDOM due to the long residence time of surface waters in the subtropical gyres with high insolation (Swan et al., 2009). Seasonal variability of vertical profiles and characteristics of fluorescent DOM in the subtropical region of the western Pacific were also explained by deep winter mixed layer and the extensive photobleaching (Omori et al., 2010, 2011). Thus, different levels of CDOM found between the subarctic and the subtropical regions in this study can be explained mainly by differences in photobleaching degree of CDOM between the regions.

Subsurface maxima of CDOM level were found at ST-1 and ST-2 in the subtropical region (Fig. 3). These maxima are possibly due to the results of photobleaching and microbial production of CDOM as discussed above. However, at the southern most ST-3, lowest level of CDOM, possibly due to extensive photobleaching, was found in the surface water $(5-10 \mathrm{~m})$ and the CDOM level increased with depth below the surface water. It should be noted that ST-3 is near the central part of the subtropical gyre, and consequently, the upper water column at ST-3 is relatively stratified throughout the year compared with ST-1 and ST-2. In addition, the upper water column at ST-3 characterized as high salinity suggests longer exposure to sunlight in the sea surface. Interestingly, in the water column between 150 to $300 \mathrm{~m}$, levels of CDOM as well as salinity and temperature were within a narrow range, suggesting that the same water mass was distributed for $150-300 \mathrm{~m}$ at the 3 stations.

\subsection{Spectral characteristics of CDOM as a biogeochemical tracer in the open ocean}

In analogy with differences in CDOM quantity due to different degrees of photobleaching, some of the qualitative parameters of CDOM also showed differences between the 
subarctic and the subtropical regions (Fig. 3). The values of $S_{275-295}$ were different between the subarctic and the subtropical regions. Such differences in $S_{275-295}$ between the two oceanic regions was consistent with the results of photoirradiation experiments, i.e., an increase in $S_{275-295}$ along with photobleaching of CDOM (Fig. 5). In addition, the lowest level of CDOM found at ST-3, possibly due to extensive photobleaching, was accompanied with the highest $S_{275-295}$. Even though changes in $S_{275-295}$ during photoirradiation experiments using oceanic DOM have scarcely been reported, an increase in $S_{275-295}$ was also observed during photo-irradiation experiment of the North Atlantic Deep Water (Stubbins et al., 2012). More recently, Helms et al. (2013) conducted a photo-irradiation experiment using deep ocean (near Hawaii) sample concentrated by reverse osmosis with electrodialysis and found that $S_{275-295}$ increased with photobleaching of deep ocean CDOM. Ortega-Retuerta et al. (2010) conducted the photo-irradiation incubations using Southern Ocean waters and found that $S_{275-295}$ exhibited a net increase over the incubation where photobleaching was the dominant process, whereas that did not show this trend in the incubations where photohumification (photoinduced transformation) was observed. Increases in $S_{275-295}$ have also been observed during photobleaching of terrestrial and coastal DOM (Helms et al., 2008; Zhang et al., 2009b; Osburn et al., 2011; Fichot and Benner, 2012). From the relationships between $S_{275-295}$ and salinity observed at the northern Gulf of Mexico, Fichot and Benner (2012) suggested that photobleaching is a major process regulating $S_{275-295}$ in surface waters regardless of origin, i.e., marine or terrigenous.

It appears $S_{275-295}$ changed slightly but did not exhibit systematic a increase/decrease trend during dark microbial incubation (Fig. 4). The slight decrease in $S_{275-295}$ was found during microbial incubation of river water (Helms et al., 2008). Fichot and Benner (2012) found the slight decrease in $S_{275-295}(1-2.4 \%)$ during microbial incubation of ambient coastal DOM. They also conducted the microbial incubation experiments of ambient coastal DOM (that $S_{275-295}$ values were $0.0168-0.0196 \mathrm{~nm}^{-1}$ ) with addition of protein-rich plankton DOM obtained from a diatom bloom (that $S_{275-295}$ was $0.0259 \mathrm{~nm}^{-1}$ ) and found that $S_{275-295}$ decreased moderately with degradation of highly labile, protein-rich plankton DOM. These experimental results suggest that $S_{275-295}$ is not changed significantly by microbial degradation (modification) of bioavailable DOM, even though highly labile, protein-rich DOM shows relatively high $S_{275-295}$ values. Therefore, $S_{275-295}$ can be used as a tracer of photochemical history of CDOM in the open ocean.

The increase in $S_{275-295}$ during photobleaching of terrestrial and coastal CDOM has been considered the result of high molecular weight CDOM into low molecular weight CDOM (Helms et al., 2008). This increase, however, could also be explained by the solar radiation spectrum and absorption spectra of CDOM. Del Vecchio and Blough (2002) found that the primary (direct) loss of CDOM absorption occurred at the irradiation wavelength, with smaller secondary (indirect) losses occurring outside the irradiation wavelength using monochromatic radiation. Using polychromatic radiation that is comparable to solar radiation, they also found that the relative loss of CDOM absorption was greater at longer wavelengths due to (1) the greater photons at longer wavelengths and (2) the higher rates of indirect absorption loss at longer wavelengths. Fichot and Benner (2012) pointed out that the $S_{275-295}$ increase with greater indirect loss of absorption at $295 \mathrm{~nm}$ compared to $275 \mathrm{~nm}$ during irradiation under the natural solar radiation, because the position of the $275-295 \mathrm{~nm}$ window is the outer edge of the incident solar spectrum. In fact, Swan et al. (2012) estimated the absorbed quanta by $\mathrm{CDOM}\left(Q_{a}\right)$ that was calculated by solar simulator spectrum and oceanic CDOM absorption spectra and found that $Q_{a}$ was sharply increased from $300 \mathrm{~nm}$, peaked at $320-325 \mathrm{~nm}$, then gradually decreased toward $450 \mathrm{~nm}$. Such spectral characteristics of solar radiation and CDOM cause less photobleaching at the shorter wavelength region, and thus, increase in $S_{275-295}$ during photobleaching of CDOM.

The difference between the subarctic and the subtropical regions was also found for $S_{R}$, implying that high $S_{R}$ values found at the subtropical waters were results of photobleaching of CDOM (Fig. 3). The $S_{\mathrm{R}}$ values, on the other hand, did not increase along with photobleaching of CDOM during photo-irradiation experiments (Fig. 5), even though increases in $S_{\mathrm{R}}$ were found during photo-irradiation of terrestrial and coastal CDOM (Helms et al., 2008). Even though $S_{350-400}$ observed for photo-irradiation experiments might have relatively large analytical errors, $S_{350-400}$ tended to increase accompanied by an increase in $S_{275-295}$ during photobleaching of CDOM, resulting the unchanged $S_{\mathrm{R}}$ values in this study (Fig. 5). Zhang et al. (2009b) reported the decrease in $S_{350-400}$ during photobleaching of lake CDOM. On the other hand, Osburn et al. (2011) found the slight increase in $S_{350-400}$ during photobleaching of lake CDOM. The different behavior, i.e., increase or decrease trend, of $S_{350-400}$ among samples submitted to photo-irradiation was also found (Helms et al., 2008). These results suggest that changes in $S_{350-400}$ during photobleaching of CDOM might depend on CDOM sources that related to compositions. $S_{350-400}$ were not different between the subarctic and the subtropical regions (Fig. 3). Such spatial characteristics of $S_{350-400}$ imply that an important factor controlling the $S_{350-400}$ value is not photobleaching of CDOM in the open ocean. In addition, Swan et al. (2012) found the photobleaching of CDOM absorption at $300-360 \mathrm{~nm}$ with simultaneous increases in the absorption at $360-500 \mathrm{~nm}$ for samples from high-nutrient low-chlorophyll regions. Thus, $S_{275-295}$ may be more appropriate given the relative insensitivity of and possible nonphotochemical influence on $S_{350-400}$ suggesting that $S_{275-295}$ is more suitable as a tracer of photochemical history of CDOM in the open ocean. 

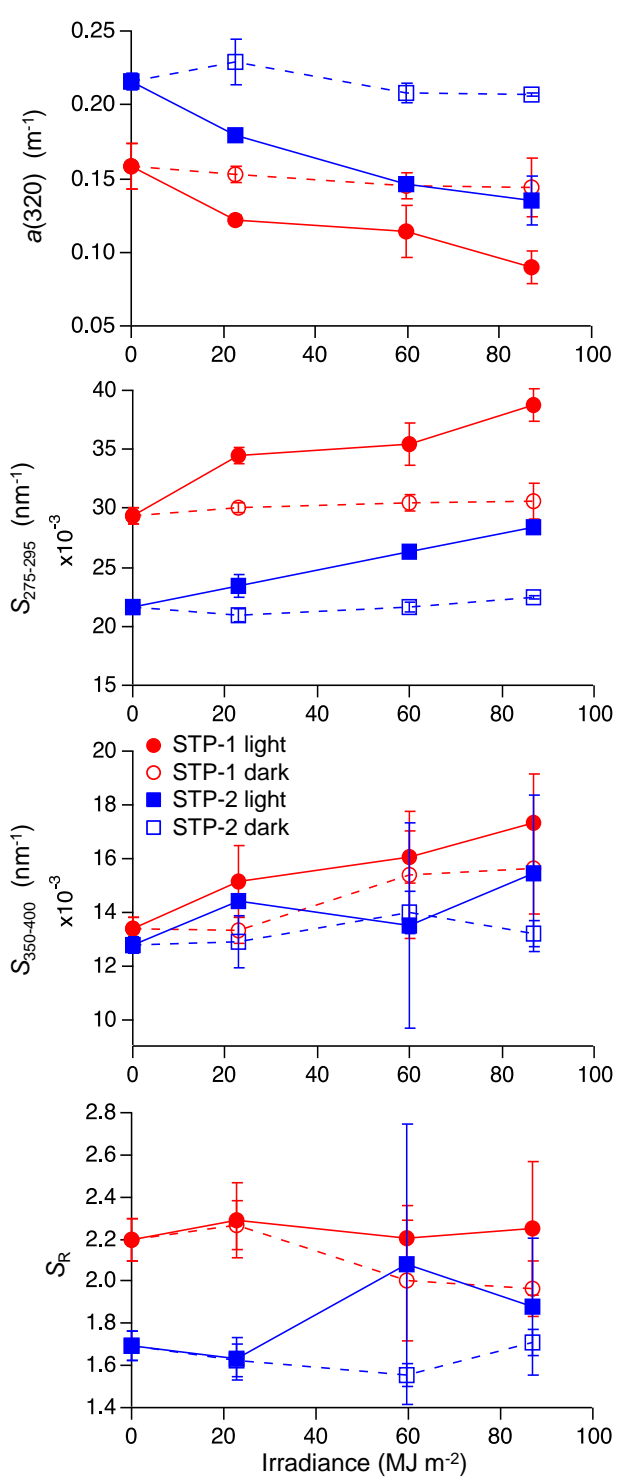

Fig. 5. Changes in $a(320), S_{275-295}, S_{350-400}$, and $S_{\mathrm{R}}$ during photo-irradiation experiments of the subtropical deep waters. Note: 23,60 , and $87 \mathrm{MJ} \mathrm{m}^{-2}$ on the $x$ axis was corresponding to 2,6 , and 13 days for the dark control experiments, respectively.

Interestingly, $S_{\mathrm{R}}$ showed subsurface maxima in the subarctic region, suggesting that newly produced CDOM has higher $S_{\mathrm{R}}$ values and/or $S_{\mathrm{R}}$ values changed during microbial degradation processes of CDOM. In our dark microbial incubation experiments, decreases in $S_{\mathrm{R}}$ due to increase in $S_{350-400}$ were evident, along with the degradation of bioavailable oceanic CDOM (Fig. 4). This result implies that $S_{\mathrm{R}}$ might be useful as a tracer of microbial reworking history of oceanic CDOM. Helms et al. (2008), on the other hand, found the decrease in $S_{\mathrm{R}}$ due to decrease in the $S_{275-295}$ and increase in the $S_{350-400}$ for degradation of terrigenous DOM. Zhang et al. (2009a) reported the increase, and then, decrease trend of $S_{\mathrm{R}}$ during lake phytoplankton degradation experiment. Such different trends of $S_{\mathrm{R}}$ during DOM degradation might be results of differences in sources, i.e., terrigenous or autochthonous. Further study is needed for evaluating the $S_{\mathrm{R}}$ as well as $S_{350-400}$ as a tracer of photochemical and/or microbial reworking history in relation to sources of CDOM.

\section{Conclusions and perspectives}

This study demonstrated that photobleaching is a primary factor controlling the $S_{275-295}$ in surface waters of the western North Pacific. The results are consistent with previous studies conducted in terrestrial aquatic and coastal environments (Helmes et al., 2008; Fichot and Benner, 2012) as well as recent photo-irradiation experiments using deep ocean water (Stubbins et al., 2012; Helms et al., 2013). Thus, as with terrestrial and coastal environments, $S_{275-295}$ can be used as a possible tracer for photochemical history of CDOM in the open ocean. Helms et al. $(2008,2013)$ pointed out that $S_{275-295}$ may be used for tracing subducted, photobleached surface water. In this study, we discussed the possible contribution of the same water mass into the lower water column at 3 stations in the subtropical region from the distributional pattern of $S_{275-295}$. The subsurface and intermediate waters, such as mode waters, have intrinsic formation regions (e.g. Suga et al., 2004) where photochemical histories of CDOM are possibly different. Thus, $S_{275-295}$ can be used for evaluating the distribution of mode waters. In addition, $S_{275-295}$ can also be used for tracing episodic upwelling, caused by events such as tropical cyclones. The vertical transport of photolabile CDOM from subsurface into surface waters might affect the primary and microbial production because photodegradation of CDOM gives rise the microbiologically labile low molecular weight compounds (Mopper and Kieber, 2002). To clarify this issue, effects of photo-degradation of CDOM with changes in $S_{275-295}$ on the biological production should be evaluated. Measurement of CDOM optical properties has often been focused on the visible region, because it is a well-recognized interfering factor for satellite remote sensing of chlorophyll $a$. Recently, CDOM has also been determined with satellite remote sensing (e.g. Sasaki et al., 2004; Matsuoka et al., 2007). Since $S_{275-295}$ can be measured with high precision and give rise useful information for marine biogeochemistry, inclusion of this analysis in future optical studies in the open ocean is highly expected.

Acknowledgements. We are grateful to K. Sugie, and captains and crews of the R/V Wakataka-maru, the R/V Tansei Maru, the R/V Hakuho Maru for their assistance with sample collection. This research was supported by grants-in-aid from JSPS (No. 22840002, 23651003, and 24681002 to Y. Yamashita; 24121003 to H. Saito.)

Edited by: A. Bricaud 


\section{References}

Biers, E. J., Zepp, R. G., and Moran, M. A.: The role of nitrogen in chromophoric and fluorescent dissolved organic matter formation, Mar. Chem., 103, 46-60, 2007.

Blough, N. L. and Del Vecchio, R.: Chromophoric DOM in the coastal environment, in: Biogeochemistry of Marine Dissolved Organic Matter, edited by: Carlson, C. and Hansell, D., Academic Press, 509-546, 2002.

Bricaud, A., Ciotti, A. M., and Gentili, B.: Spatial-temporal variations in phytoplankton size and colored detrital matter absorption at global and regional scales, as derived from twelve years of SeaWiFS data (1998-2009), Glob. Biogeochem. Cy., 26, GB1010, doi:10.1029/2010GB003952, 2012.

Carder, K. L., Steward, R. G., Harvey, G. R., and Ortner, P. B.: Marine humic and fulvic acids: Their effects on remote sensing of ocean chlorophyll, Limnol. Oceanogr., 34, 68-81, 1989.

Del Vecchio, R. and Blough, N. V.: Photobleaching of chromophoric dissolved organic matter in natural waters: kinetics and modeling, Mar. Chem., 78, 231-253, 2002.

Endo, H., Yoshimura, T., Kataoka, T., and Suzuki, K.: Effects of $\mathrm{CO}_{2}$ and iron availability on phytoplankton and eubacterial community compositions in the northwest subarctic Pacific, J. Exp. Mar. Biol. Ecol., 439, 160-175, 2013.

Fichot, C. G., Sathyendranath, S., and Miller, W. L.: SeaUV and SeaUVC: Algorithms for the retrieval of UV/Visible diffuse attenuation coefficients from ocean color, Remote Sens. Environ., 112, 1584-1602, 2008.

Fichot, C. G. and Benner, R.: A novel method to estimate DOC concentrations from CDOM absorption coefficients in coastal waters, Geophys. Res. Lett., 38, L03610, doi:10.1029/2010GL046152, 2011.

Fichot, C. G. and Benner, R.: The spectral slope coefficient of chromophoric dissolved organic matter $\left(S_{275-295}\right)$ as a tracer of terrigenous dissolved organic carbon in river-influenced ocean margins, Limnol. Oceanogr., 57, 1453-1466, 2012.

Fichot, C. G., Kaiser, K., Hooker, S. B., Amon, R. M. W., Babin, M., Bélanger, S., Walker, S. A., and Benner, R.: Pan-Arctic distributions of continental runoff in the Arctic Ocean, Sci. Rep., 3, 1053, doi:10.1038/srep01053 2013.

Granskog, M. A.: Changes in spectral slopes of colored dissolved organic matter absorption with mixing and removal in a terrestrially dominated marine system (Hudson Bay, Canada), Mar. Chem., 134, 10-17, 2012.

Green, S. A. and Blough, N. V.: Optical absorption and fluorescence properties of chromophoric dissolved organic matter in natural waters, Limnol. Oceanogr., 39, 1903-1916, 1994.

Guéguen, C., Granskog, M. A., McCullough, G., and Barber, D. G.: Characterisation of colored dissolved organic matter in Hudson Bay and Hudson Strait using parallel factor analysis, J. Mar. Syst., 88, 423-433, 2011.

Häder, D.-P., Kumar, H. D., Smith, R. C., and Worrest, R. C.: Effects on aquatic ecosystems, J. Photochem. Photobiol. B-Biol., 46, 5368, 1998.

Hasegawa, T., Kasai, H., Ono, T., Tsuda, A., and Ogawa, H.: Dynamics of dissolved and particulate organic matter during the spring bloom in the Oyashio region of the western subarctic Pacific Ocean, Aquat. Microb. Ecol., 60, 127-138, .2010.

Helms, J. R., Stubbins, A., Ritchie, J. D., Minor, E. C., Kieber, D. J., and Mopper, K.: Absorption spectral slopes and slope ratios as indicators of molecular weight, source, and photobleaching of chromophoric dissolved organic matter, Limnol. Oceanogr., 53, 955-969, 2008.

Helms, J. R., Stubbins, A., Perdue, E. M., Green, N. W., Chen, H., and Mopper, K.: Photochemical bleaching of oceanic dissolved organic matter and its effect on absorption spectral slope and fluorescence, Mar. Chem., 155, 81-91, 2013.

Herndl G. J., Muller-Niklas, G., and Frick, J.: Major role of ultraviolet-B in controlling bacterioplankton growth in the surface layer of the ocean, Nature, 361, 717-719, 1993.

Kawai, H.: Hydrography of the Kuroshio Extention, in: Kuroshio, edited by: Stommel H., Yoshida K., University of Tokyo Press, 235-352, 1972.

Kitidis, V., Stubbins, A. P., Uher, G., Goddard, R. C. U., Law, C. S., and Woodward, E. M. S.: Variability of chromophoric organic matter in surface waters of the Atlantic Ocean, Deep-Sea Res. Pt. II, 53, 1666-1684, 2006.

Kobari, T., Mitsui, K., Ota, T., Ichinomiya, M., and Gomi, Y.: Response of heterotrophic bacteria to the spring phytoplankton bloom in the Oyashio region, Deep-Sea Res. Pt. II, 57, 16711678, 2010.

Kudo, I., Noiri, Y., Cochlan, W. P., Suzuki, K., Aramaki, T., Ono, T., and Nojiri, Y.: Primary productivity, bacterial productivity and nitrogen uptake in response to iron enrichment during the SEEDS II, Deep-Sea Res. Pt. II, 56, 2755-2766, 2009.

Matsuoka, A., Huot, Y., Shimada, K., Saitoh, S., and Babin, M.: Bio-optical characteristics of the western Arctic Ocean: implications for ocean color algorithms, Can. J. Remote Sens., 33, 503-518, 2007.

Mladenov, N., Sommaruga, R., Morales-Baquero, R., Laurion, I., Camarero, L., Diéguez, M. C., Camacho, A., Delgado, A., Torres, O., Chen, Z., Felip, M., and Reche, I.: Dust inputs and bacteria influence dissolved organic matter in clear alpine lakes, Nat. Commun., 2, 405, doi:10.1038/ncomms1411, 2011.

Mopper, K. and Kieber, D. J.: Photochemistry and the cycling of carbon, sulfer, nitrogen and phosphorus, in: Biogeochemistry of Marine Dissolved Organic Matter, edited by: Carlson, C. and Hansell, D., Academic Press, 455-508, 2002.

Nelson, N. B. and Siegel, D. A.: Chromophoric DOM in the open ocean, in: Biogeochemistry of Marine Dissolved Organic Matter, edited by: Carlson, C. and Hansell, D., Academic Press, 547578, 2002.

Nelson, N. B. and Siegel, D. A.: The global distribution and dynamics of chromophoric dissolved organic matter, Annu. Rev. Mar. Sci., 5, 447-476, 2013.

Nelson, N. B., Siegel, D. A., and Michaels, A. F.: Seasonal dynamics of colored dissolved material in the Sargasso Sea, Deep-Sea Res. Pt.I, 45, 931-957, 2002.

Nelson, N. B., Carlson, C. A., and Steinberg, D. K.: Production of chromophoric dissolved organic matter by Sargasso Sea microbes, Mar. Chem., 89, 273-287, 2004.

Nelson, N. B., Siegel, D. A., Carlson, C. A., Swan, C., Smethie, Jr., W. M., and Khatiwala, S.: Hydrography of chromophoric dissolved organic matter in the North Atlantic, Deep-Sea Res. Pt. I, 54, 710-731, 2007.

Nelson, N. B., Siegel, D. A., Carlson, C. A., and Swan, C. M.: Tracing global biogeochemical cycles and meridional overturning circulation using chromophoric dissolved organic matter, Geophys. Res. Lett., 37, L03610, doi:10.1029/2009GL042325, 2010. 
Omori, Y., Hama, T., Ishii, M., and Saito, S.: Relationship between the seasonal change in fluorescent dissolved organic matter and mixed layer depth in the subtropical western North Pacific, J. Geophys. Res., 115, C06001, doi:10.1029/2009JC005526, 2010.

Omori, Y., Hama, T., Ishii, M., and Saito, S.: Vertical change in the composition of marine humic-like fluorescent dissolved organic matter in the subtropical western North Pacific and its relation to photoreactivity, Mar. Chem., 124, 38-47, 2011.

Ortega-Retuerta, E., Frazer, T. K., Duarte, C. M., Ruiz-Halpern, S., Tovar-Sánchez, A., Arrieta, J. M., and Reche, I.: Biogeneration of chromophoric dissolved organic matter by bacteria and krill in the Southern Ocean, Limnol, Oceanogr., 54, 1941-1950, 2009.

Ortega-Retuerta, E., Reche, I., Pulido-Villena, E., Agustí, S., and Duarte, C. M.: Distribution and photoreactivity of chromophoric dissolved organic matter in the Antarctic Peninsula (Southern Ocean), Mar. Chem., 118, 129-139, 2010.

Osburn, C. L., Wigdahl, C. R., Fritz, S. C., and Saros, J. E.: Dissolved organic matter composition and photoreactivity in prairie lakes of the US Great Plains, Limnol. Oceanogr., 56, 2371-2390, 2011.

Romera-Castillo, C., Álvarez-Salgado, X., Galí, M., Gasol, J. M., and Marrasé, C.: Combined effect of light exposure and microbial activity on distinct dissolved organic matter pools. A seasonal field study in an oligotrophic coastal system (Blanes Bay,NW Mediterranean), Mar. Chem., 148, 44-51, 2013.

Saito, H., Tsuda, A., and Kasai, H.: Nutrient and plankton dynamics in the Oyashio region of the western subarctic Pacific Ocean, Deep-Sea Res. Pt. II, 49, 5463-5486, 2002.

Sasaki, H, Siswanto, E., Nishiuchi, K., Tanaka, K., Hasegawa, T., and Ishizaka, J.: Mapping the low salinity Changjiang Diluted Water using satellite-retrieved colored dissolved organic matter $(\mathrm{CDOM})$ in the East China Sea during high river flow season, Geophys. Res. Lett., 35, L04604, doi:10.1029/2007GL032637, 2004.

Shank, C. G., Lee, R., Vähätalo, A., Zepp, R. G., and Bartels, E.: Production of chromophoric dissolved organic matter from mangrove leaf litter and floating Sargassum colonies, Mar. Chem., 119, 172-181, 2010.

Shank, C. G. and Evans, A.: Distribution and photoreactivity of chromophoric dissolved organic matter in northern Gulf of Mexico shelf waters, Cont. Shelf Res., 31, 1128-1139, 2011.

Siegel, D. A., Maritorena, S., Nelson, N. B., Hansell, D. A., and Lorenzi-Kayser, M.: Global distribution and dynamics of colored dissolved and detrital organic materials, J. Geophys. Res., 107, C123228, doi:10.1029/2001JC000965, 2002.

Smith, R. C., Prezelin, B. B., Baker, K. S., Bidigare, R. R., Boucher, N. P., Coley, T., Karentz, D., MacIntyre, S., Matlick, H. A., Menzies, D., Ondrusek, M., Wan, Z., and Waters, K. J.: Ozone depletion: ultraviolet radiation and phytoplankton biology in Antarctic waters, Science, 255, 952-959, 1992.

Spencer, R. G. M., Butler, K. D., and Aiken, G. R.: Dissolved organic carbon and chromophoric dissolved organic matter properties of rivers in the USA, J. Geophys, Res., 117, G03001, doi:10.1029/2011JG001928, 2012.

Stedmon, C. A., Markager, S., and Kaas, H.: Optical Properties and signatures of chromophoric dissolved organic matter (CDOM) in Danish coastal waters, Estuar. Coast. Shelf Sci., 51, 267-278, 2000 .
Steinberg, D. K., Nelson, N. B., Carlson, C. A., and Prusak, A. C.: Production of chromophoric dissolved organic matter (CDOM) in the open ocean by zooplankton and the colonial cyanobacterium Trichodesmium spp, Mar. Ecol. Prog. Ser., 267, 45-56, 2004.

Stubbins, A., Niggemann, J., and Dittmar, T.: Photo-lability of deep ocean dissolved black carbon, Biogeosciences, 9, 1661-1670, doi:10.5194/bg-9-1661-2012, 2012.

Suga, T., Motoki, K., and Aoki, Y.: The North Pacific Climatology of Winter Mixed Layer and Mode Waters, J. Phys. Oceanogr., 34, 3-22, 2004.

Swan, C. M., Siegel, D. A., Nelson, N. B., Carlson, C. A., and Nasir, E.: Biogeochemical and hydrographic controls on chromophoric dissolved organic matter distribution in the Pacific Ocean, DeepSea Res. Pt. I, 56, 2175-2192, 2009.

Swan, C. M., Nelson, N. B., Siegel, D. A., and Kostadinov, T. S.: The effect of surface irradiance on the absorption spectrum of chromophoric dissolved organic matter in the global ocean, Deep-Sea Res. Pt. I, 63, 52-64, 2012.

Twardowski, M. S., Boss, E., Sullivan, J. M., and Donaghay, P. L.: Modeling the spectral shape of absorption by chromophoric dissolved organic matter, Mar. Chem., 89, 69-88, 2004.

Vernet, M. and Whitehead, K.: Release of ultraviolet-absorbing compounds by the red-tide dinoflagellate Lingulodinium polyedra, Mar. Biol., 127, 35-44, 1996.

Welschmeyer, N. A.: Fluorometric analysis of chlorophyll $a$ in the presence of chlorophyll $b$ and phaeopigments, Limnol. Oceanogr., 39, 1985-1992, 1994.

Yamashita, Y. and Tanoue, E.: In situ production of chromophoric dissolved organic matter in coastal environments, Geophys. Res. Lett., 31, L14302, doi:10.1029/2004GL019734, 2004.

Yamashita, Y. and Tanoue, E.: Production of bio-refractory fluorescent dissolved organic matter in the ocean interior, Nat. Geosci., 1, 579-582, 2008.

Yamashita, Y. and Tanoue, E.: Basin scale distribution of chromophoric dissolved organic matter in the Pacific Ocean, Limnol. Oceanogr., 54, 598-609, 2009.

Yamashita, Y., Maie, N., Briceño, H., and Jaffé R.: Optical characterization of dissolved organic matter in tropical rivers of the Guayana Shield, Venezuela, J. Geophys. Res., 115, G00F10, doi:10.1029/2009JG000987, 2010a.

Yamashita, Y., Scinto, L., Maie, N., and Jaffé, R.: Dissolved organic matter characteristics across a subtropical wetland's landscape: Application of optical properties in the assessment of environmental dynamics, Ecosystems, 13, 1006-1019, 2010b.

Ysuda, I.: North Pacific Intermediate Water: Progress in SAGE (SubArctic Gyre Experiment) and Related Projects, J. Oceanogr., 60, 385-395, 2004.

Zhang, Y., van Dijk, M. A., Liu, M., Zhu, G., and Qin, B.: The contribution of phytoplankton degradation to chromophoric dissolved organic matter (CDOM) in eutrophic shallow lakes: Field and experimental evidence, Water Res., 43, 4685-4697, 2009a.

Zhang,Y., Liu, M., Qin, B., and Feng, S.: Photochemical degradation of chromophoric-dissolved organic matter exposed to simulated UV-B and natural solar radiation, Hydrobiologia, 627, 159168, 2009b. 